\title{
Integration of Cockpit Displays for Surface Operations: The Final Stage of a Human-Centered Design Approach
}

\author{
Becky L. Hooey, \\ Monterey Technologies, Inc. / NASA Ames Research Center \\ David C. Foyle, \\ NASA Ames Research Center \\ Anthony D. Andre \\ San Jose State University / NASA Ames Research Center
}

Copyright (? 2000 Society of Automotive Engineers, Inc.

\begin{abstract}
A suite of cockpit navigation displays for low-visibility airport surface operations has been designed by researchers at NASA Ames Research Center following a human-centered process. This paper reports on the final research effort in this process that examined the procedural integration of these technologies into the flight deck. Using NASA Ames' high-fidelity Advanced Concepts Flight Simulator, eighteen airline crews completed fourteen low-visibility (RVR 1000') land-andtaxi scenarios that included both nominal (i.e., hold short of intersections, route amendments) and off-nominal taxi scenarios designed to assess how pilots integrate these technologies into their procedures and operations. Recommendations for integrating datalink and cockpit displays into current and future surface operations are provided.
\end{abstract}

\section{INTRODUCTION}

A suite of cockpit navigation displays called the Taxiway Navigation and Situation Awareness (T-NASA) system has been developed by researchers at NASA Ames Research Center [see 1]. The goal of this technology was to improve the efficiency of airport surface operations for commercial aircraft operating in weather conditions to CAT IIIB while maintaining a high degree of safety.

A human-centered approach [2] was adopted to guide the design process to ensure that the system would meet its objectives of increased efficiency and safety, while at the same time consider the capabilities and limitations of the flight crew. The T-NASA design process involved over 300 commercial pilots participating in part-task simulations [3, 4, 5, 6 7], high- fidelity simulations $[8,9,10]$, and flight-tests at Atlanta Hartsfield International Airport [11, 12]. The humancentered design process that was used to develop the T-NASA cockpit display suite is presented in Figure 1 and summarized below.

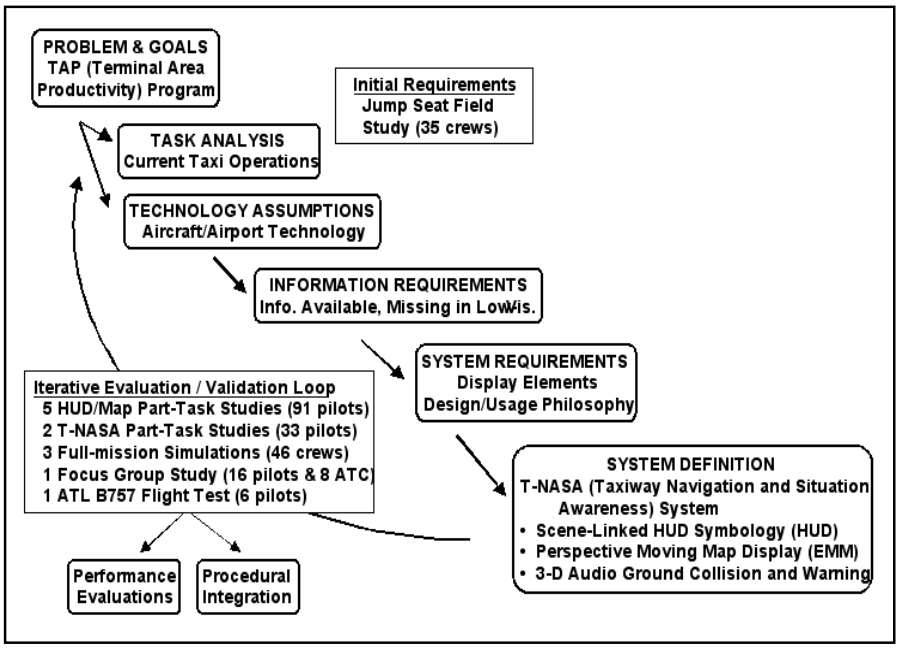

Figure 1. Human-Centered Design Process

TASK ANALYSIS - The first step in the human-centered design process was to develop a thorough understanding of problems and issues associated with current taxi operations from a pilot's perspective. In total, 35 crews were observed in the cockpit environment during normally scheduled commercial flights [13] and 16 pilots participated in a series of scenario-based focus groups [14]. Five classes of problems were observed during these analyses of current taxi operations:

- Degraded situational awareness due to the loss of visual cues in low-visibility resulting in lower taxi 
speeds, increased workload, and decreased confidence in taxi abilities.

- Navigation problems due to deficiencies in the visual airport surface environment (signs and markings) resulting in off-route errors impacting both safety and taxi efficiency.

- Ineffective communications between ground control and the cockpit resulting in radio frequency congestion, call sign confusion, and delays during clearance issuance.

- Increased workload due to frequent route amendments, hold short instructions, and expedited runway crossings.

- Increased complexities due to the need to sequence with other aircraft on the airport surface.

TECHNOLOGY ASSUMPTIONS - Assumptions were made about technology requirements and availability. The components were originally outlined in [1] and subsequently updated as technology advancements have been made. The following candidate technologies were proposed:

- Flight deck displays. Three display options available to commercial carriers were considered. Head-Up Displays (HUDs) are installed in many commercial aircraft. Although these displays are widely accepted for landing and take-off operations [15], none are currently used for taxi operations. Panelmounted electronic moving maps (EMMs) could be integrated easily into glass-equipped aircraft, and share real estate with the current navigation display (which is not required for surface operations). Finally, the audio modality was considered a likely candidate for critical alerts and warnings, as consistent with airborne phases of flights.

- Differential global positioning systems (DGPS) and on-board electronic airport databases to provide information about the pilots' position relative to the taxiways and runways.

- Ground-based surveillance (such as ASDE-3 RADAR and AMASS) that provide surveillance data to air traffic control (ATC) and to any equipped aircraft/vehicle via datalink to depict airport traffic on the cockpit displays.

- A controller-pilot datalink system that allows ATC to issue routing and control instructions via an independent link. Currently, datalink is used for communication in oceanic operations [16]. Little research has addressed the feasibility of datalink for surface operations. However, it is expected that aircraft in the future will be increasingly equipped with datalink technologies, displays, and controls. This will allow for an easy transition for use in surface operations.

A proof of technology field test was conducted at Atlanta Hartsfield International Airport in 1997, which successfully demonstrated the viability of these technologies [11]. Also, an investigation was conducted to determine the requirements for outfitting both classic and glass cockpit aircraft with these technologies [17].

INFORMATION REQUIREMENTS - A set of information requirements was developed to define the precise nature of information required by the pilots. As the goal was to increase surface operations efficiency in low-visibility, this analysis focused on determining the information that pilots currently have available in clear-visibility, but which is degraded in low-visibility. As described in [1] the information requirements were broken into two classes of information: Global awareness and local awareness. Global awareness information includes items such as distant and up-coming intersections, navigational references such as gates, concourses, and terminals, and the location and identification of other aircraft on the airport surface. In low-visibility this global awareness information is often unavailable to pilots. Local awareness information includes visual cues that pilots use to control the aircraft and navigate in the immediate area. These local awareness cues such as taxiway centerlines and lights, taxiway edges, and taxiway signage, tend to be degraded in low-visibility. Thus information requirements were established to replace the global awareness information that is absent, and augment the local awareness information that is degraded.

SYSTEM REQUIREMENTS - Having established the information required for current taxi operations, the degradation imposed during low-visibility conditions, and utilizing research on pilot interactions with navigational displays [i.e., 18, 19], a set of desired system characteristics and a design philosophy was determined [1]. The following represent the four main design philosophy goals:

- Augment global awareness cues by providing a head-down, perspective-view, electronic moving map (EMM) designed for navigational awareness but not steering control or centerline tracking.

- Enhance local guidance visual cues by augmenting the out-the-window view virtually and conformally on the head-up display (HUD).

- Capitalize on pilots' experience and expertise by reinstating visual cues so pilots can use the same local guidance cues in low-visibility as they do in clear weather.

- Support "eyes-out" taxi operations by providing local guidance via the HUD and requiring only occasional glances head-down to the moving map to maintain situation awareness by designing the map to be used for navigation support, rather than closed-loop control. Include 3-D, spatially-localized audio to alert pilots to traffic.

SYSTEM DEFINITION - The information requirements were translated into a set of display interface 
components and requirements resulting in a prototypical cockpit display system called the Taxiway Navigation and Situation Awareness (T-NASA) cockpit display suite [1], as shown in Figure 2. This system is comprised of an electronic moving map (EMM), a head-up display (HUD), and auditory alerts and warnings. The EMM and HUD are designed to complement each other, with the EMM serving as a secondary display to support global navigational awareness and the HUD serving as a primary navigation display to support local navigation. This allows the captain to ascertain local guidance cues from the HUD while remaining eyes out, and allows both pilots to gather global awareness information as needed by glancing at the EMM.

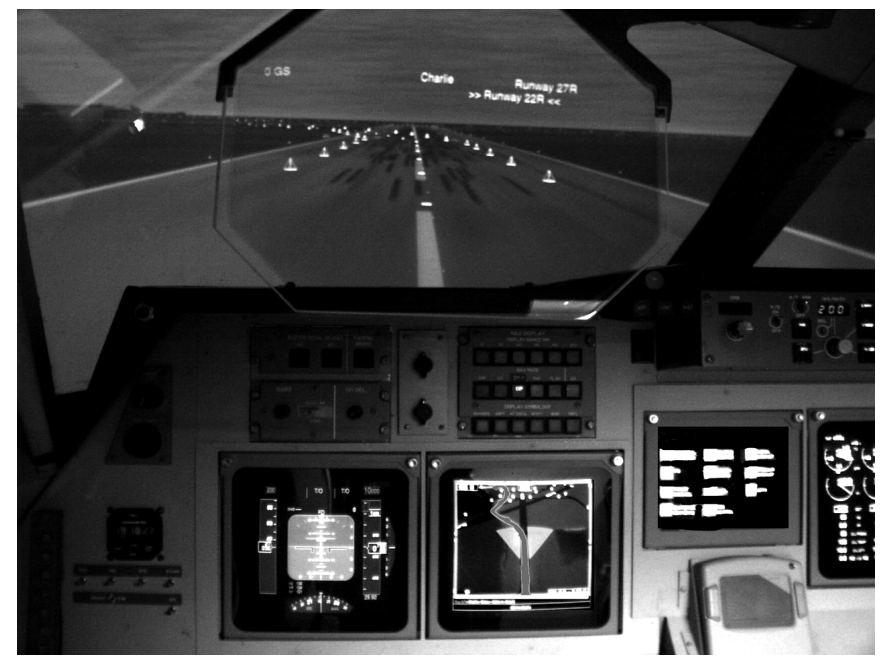

Figure 2. T-NASA Displays (HUD and EMM)

T-NASA EMM - The EMM (Figure 3) provides both pilots with routing, guidance, and surveillance information in a head-down moving map format located in the multifunction display that is also used to present the navigation display. The EMM is available while airborne upon pilot demand and presents a 'runway-up' view of the airport surface. Runway occupancy bars highlight occupied runways using AMASS-like technology. Immediately upon touchdown, the navigation display automatically switches to the EMM in a track-up perspective view (from above and behind the aircraft). The EMM depicts the ownship position relative to the airport surface. Consistent with the design philosophy of enabling eyes-out taxiing, the map is not intended for primary control of the aircraft. As such, the ownship icon purposefully does not depict wing span, or the location of the aircraft gear. Routing and guidance information is presented via a thick magenta strip that highlights the cleared taxi route. Again, the magenta strip does not depict centerline information to encourage the use of the EMM as a secondary display for general navigational awareness information only, and not primary control of the aircraft. The map also supports hold short directives by depicting a yellow flashing hold bar for both ownship and traffic. Also, the cleared route beyond the hold bar is shown in yellow. Real-time traffic icons depict traffic located on the airport surface. A three-stage color- coding scheme is implemented, similar to TCAS, that indicates potential traffic incursion threats. The map has four zoom levels, which each pilot can independently adjust to his/her own preference, in addition to an airport and taxi-specific ATIS screen.

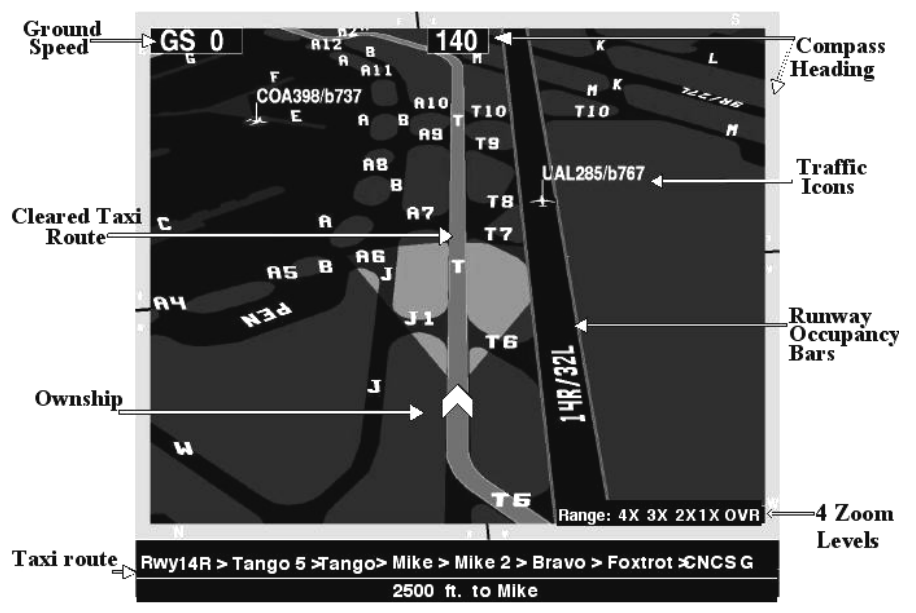

Figure 3. T-NASA EMM

T-NASA HUD - The T-NASA HUD symbology (Figure 4), uses scene-linked symbology [1, 20] overlaid upon the airport surface to augment local guidance cues. The scene-linked symbology appears to integrate perceptually with the actual out-the-window scene, thus providing intuitive, or ecological cues to support local guidance. Specifically, a series of virtual cones are located along both edges of the cleared taxiway, and a series of squares overlay the centerline of the taxiway to mark the cleared taxi route. Consistent with the design philosophy, the HUD symbology augments visual cues that are degraded in low-visibility and provides information that the pilot normally utilizes during clearvisibility conditions.

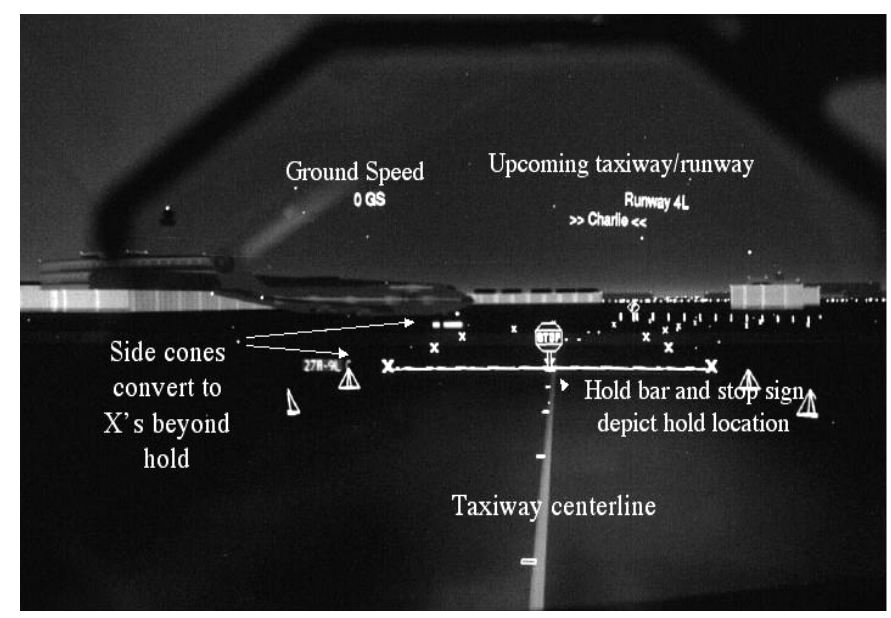

Figure 4. T-NASA HUD

The HUD also displays ground speed in the upper left corner, and a textual display intended to promote awareness of location on the airport surface in the upper right corner. Turns are denoted by virtual turn signs that indicate the angle of the turn. Directional flag poles are placed beyond the turn to provide a visual reference 
while completing a turn, as the side cones drop from the limited field of view inherent in the HUD [21]. The HUD supports ATC-issued hold short commands by depicting a virtual hold bar which overlays the hold position on the taxiway and a virtual 'stop sign' to further increase the salience of the hold short instruction. Beyond the hold bar, the virtual cones are replaced with X's to allow preview of the upcoming route beyond the hold bar, but distinguish it from the cleared route. Once ATC removes the hold, the X's convert to the virtual cones. The HUD does not present traffic information in order to avoid clutter and obscuration of relevant out-the-window objects. Therefore, when necessary, traffic information is gathered by glances to the EMM.

T-NASA Audio Alerts - Directional audio warnings and alerts are presented to provide additional situational awareness regarding traffic location and potential problems. The system incorporates three audio alerts: 1) An audio tone followed by the words "Traffic - Traffic" issued to warn of impending traffic incursions. This alert is directional, in that, if the traffic threat is approaching from the right, the audio alert is presented in the right earphone to direct attention to the appropriate location on the airport surface. 2) An audio tone followed by the words "Hold Short" is issued when the ownship crosses an active hold bar and 3) An audio tone followed by the words "Off Route" sounds when the ownship travels off the cleared taxi route.

\section{QUANTIFYING T-NASA BENEFITS}

Throughout the human-centered design process, several human-in-the-loop studies were conducted to assess and quantify the benefits of T-NASA. A high-fidelity simulation [9] demonstrated performance advantages for T-NASA in both low-visibility (Runway Visual Range, RVR, 700') and night taxi conditions. Specifically, this simulation demonstrated that T-NASA increased forward taxi speed by $21 \%$ and reduced navigation errors by nearly $100 \%$. A flight test at Atlanta's Hartsfield International Airport was a successful proof of technology demonstration [11, 12], and found that T-NASA improved the efficiency of airport surface operations by reducing total taxi time, reducing mental navigation workload, increasing situation awareness, improving communications, increasing taxi efficiency, and increasing safety.

\section{INTEGRATING T-NASA INTO THE COCKPIT}

The human-centered design process does not end with a well-designed interface, nor is it sufficient to demonstrate achievement of the anticipated safety and efficiency benefits. While both are important, it is also necessary to address the integration of the technologies into the intended environment.
Problems can arise from unanticipated interactions between the technology, the operator, and the environment. Often these are not problems inherent to the technologies themselves, but due to their involvement in a larger complex and distributed system [22]. For example, problems such as false alarms from automated alerting systems (e.g., TCAS), automated systems that provide inadequate feedback to the operator (e.g., the FMS: [23]), and the automation that fails 'silently' without salient indications, suggest technology integration problems [24]. Understanding these potential interactions is necessary to ensure the successful integration of these new technologies.

Further, much research on cockpit automation has revealed that automation can have subtle and often unanticipated effects on human performance [25]. Examples of automation-related problems include new forms of errors [26]; unbalanced trust and mistrust [27], over-trust [28]; reduced situational awareness [29], and loss of team cooperation [30]. These problems can produce unanticipated costs that can reduce the intended efficiency and safety benefits of the system.

Integrating T-NASA into the intended operational environment is no exception to the above problems and concerns. Like any new technology, it is anticipated that incorporating T-NASA into the cockpit will change the nature of navigation, and communication for pilots. Thus, it is important to anticipate how the technologies may be deployed and integrated into surface operations. In designing the T-NASA interface, we have implied the use of datalink to communicate the taxi clearance and other information between ATC and the flight deck. It is necessary then to examine the potential interactions that are created by implementing T-NASA in a datalinked environment. Also, T-NASA interacts with external components such as surveillance radar, datalink transmission technologies, and ATC -- all of which may have less than perfect reliability at any given time, or may be prone to error. Therefore, it is important to anticipate any effects that the technologies may introduce such as new errors, and issues associated with trust, complacency, and situational awareness. If this is done before systems such as T-NASA are actually implemented, there is an opportunity to make iterative design changes to the interface, as well as to gain insight into the training and operational procedures required to insure successful integration.

\section{CURRENT STUDY}

The final stage in this human-centered design effort is a high-fidelity simulation to evaluate the impact that implementing these technologies might have on current day operations and piloting procedures. Based on a series of focus groups involving both pilots and controllers [14], the following procedural issues were considered in this high-fidelity simulation effort: 
- The possibility that traffic may be missed by a radar system, and the subsequent consequences if an aircraft is 'lost' by the surveillance system.

- The impact of presenting traffic visually on the EMM rather than via party-line voice communications.

- The result on crew coordination of providing information to the captain in the HUD which the first officer cannot see.

- The potential requirement for new error-checking procedures to counter more sources of clearance information.

- The effect of presenting taxi clearances visually (via datalink text) rather than verbally (via radio).

\section{METHOD}

PARTICIPANTS - Eighteen crews, consisting of one captain and one first officer from the same aircraft type and airline, participated in this high-fidelity simulation. Pilots represented six commercial airlines. All pilots were current in glass-equipped aircraft with a mean of 2645 hours logged. Five of the captains reported experience flying with HUDs, ranging from 5 to $2000 \mathrm{hrs}$.

APPARATUS - The simulation was conducted in NASA Ames' high-fidelity Advanced Concepts Flight Simulator (ACFS) which emulates a wide-body, T-Tail, low wing aircraft with twin turbofan engines. The flight deck, a configurable generic glass cockpit, contains advanced flight systems including touch sensitive electronic checklists, and programmable flight displays. A Flight Safety International VITAL VIIli image generator, providing an 180-deg field of view with full cross-cockpit viewing capability generated the out-the-window view. Radio communication was provided by a confederate controller who served as both the local and ground controller. Also, a confederate pseudo-pilot was used to represent the pilots of all other aircraft in the airspace and on the airport surface. To ensure consistency in content and timing of ATC to pilot communications, both the controller and pseudo-pilot read from a teleprompter script that generated instructions to be vocalized to correspond with real-time traffic movements. Controller and pseudo-pilot communication onset and offset times were recorded in the data stream to allow for reliability and delay assessments.

Software was developed to serve as the experimental scenario generating and run-time environment. This software generated ownship routes and clearances, controlled individual traffic pieces (start, stop, speed change, and speed match to ownship), triggered datalink transmissions, controller and pseudo-pilot teleprompt messages, and audio alerts. The software allowed for real-time monitoring of ownship and traffic paths and allowed experimenters to override traffic to prevent unplanned incursions.
T-NASA Flight Deck Display - The ACFS display cockpit was configured to accommodate the T-NASA suite of displays, including the HUD, EMM, auditory alerts, and datalink display. The T-NASA HUD symbology was presented on a Flight Dynamics HUD, consisting of a semi-transparent silvered glass combiner measuring 24 $\mathrm{cm}$ in height and $20.4 \mathrm{~cm}$ in width. The HUD was mounted over the left seat, as is standard in all U.S. HUD-equipped airlines. The HUD provided typical airborne and landing symbology [15]. Upon runway turnoff, the HUD switched to the T-NASA taxi symbology which utilized scene-linked symbology $[1,20]$ to display the cleared taxi route, as described above. The EMM was available on both pilots' navigation displays and presented navigation and traffic information in a headdown moving map format. The EMM was available both airborne for runway occupancy information and route preview, as well as on the ground for taxi operations. The T-NASA audio alerts were presented via headphones provided to each crew member. The headphones allowed for the spatialized (3-D) traffic alerts, as well as non-directional off-route and hold short alerts. A datalink interface, modeled after the B777 specifications [31], was added to the ACFS display suite. The arrival of a message was annunciated by an aural alert (datalink chime) and visual alert on the upper Engine Instrument Crew Alert System (EICAS). The text message appeared on the centrally-mounted lower EICAS. Both pilots were able to respond to the datalink message using response buttons mounted on the glareshield. The two response options were: 'Accept' to acknowledge the message and 'Reject' when unable to comply. Pilots were also able to view a log of all datalink messages.

EXPERIMENTAL DESIGN - As shown in Table 1, each crew received three blocks of trials ordered according to a Latin Square design. Each crew completed currentday operations trials and one of two possible deployment approaches: Transition or Advanced. These deployment approaches, developed from focus groups with pilots and air traffic controllers [14], represent two possible ways in which the technology may be implemented in the near (transition) and distant (advanced) future. Group 1 received the Transition Deployment in which ATC communications were issued by both voice and datalink, and taxi clearances were issued after runway turn off. This deployment was designed to allow for mixed-equipped fleets which may occur as technologies are gradually adopted by airlines and airports. Group 2 received the Advanced Deployment in which ATC communications were issued by datalink only, and taxi clearances were issued while airborne. This advanced deployment promises greater efficiency benefits, but requires substantial modifications to current operations. We acknowledge that this deployment is futuristic and can only be successful if taxi clearances can be determined and issued in advance so as to not disrupt critical approach and landing procedures. 
Table 1. Experimental Design

\begin{tabular}{|c|c|c|c|}
\hline \multirow{4}{*}{ Group 1} & \multirow{2}{*}{$\begin{array}{c}\text { CURRENT } \\
\text { OPERATIONS } \\
\text { Voice, Jeppesen Chart }\end{array}$} & \multicolumn{2}{|c|}{$\begin{array}{l}\text { FUTURE OPERATIONS: TRANSITION } \\
\text { Voice + DL }\end{array}$} \\
\hline & & No T-NASA & T-NASA \\
\hline & $\begin{array}{l}\text { No Event } \\
\text { Hold Short } \\
\text { Route Amendment }\end{array}$ & $\begin{array}{l}\text { No Event } \\
\text { Hold Short } \\
\text { Route Amendment }\end{array}$ & $\begin{array}{l}\text { No Event } \\
\text { Hold Short } \\
\text { Route Amendment }\end{array}$ \\
\hline & Clearance Error & $\begin{array}{l}\text { Clearance Information Usage } \\
\text { EMM Usage Event }\end{array}$ & $\begin{array}{l}\text { Clearance Information Usage } \\
\text { EMM Usage Event + HUD Usage Event }\end{array}$ \\
\hline
\end{tabular}

\begin{tabular}{|c|c|c|c|}
\hline \multirow{4}{*}{ Group 2} & \multirow{2}{*}{$\begin{array}{c}\text { CURRENT } \\
\text { OPERATIONS } \\
\text { Voice, Jeppesen Chart }\end{array}$} & \multicolumn{2}{|c|}{$\begin{array}{l}\text { FUTURE OPERATIONS: ADVANCED } \\
\text { DL only }\end{array}$} \\
\hline & & No T-NASA & T-NASA \\
\hline & $\begin{array}{l}\text { No Event } \\
\text { Hold Short } \\
\text { Route Amendment }\end{array}$ & $\begin{array}{l}\text { No Event } \\
\text { Hold Short } \\
\text { Route Amendment }\end{array}$ & $\begin{array}{l}\text { No Event } \\
\text { Hold Short } \\
\text { Route Amendment }\end{array}$ \\
\hline & Clearance Error & $\begin{array}{l}\text { Clearance Information Úsage } \\
\text { EMM Usage Event }\end{array}$ & $\begin{array}{l}\text { Clearance Information Usage } \\
\text { EMM Usage Event + HUD Usage Event }\end{array}$ \\
\hline
\end{tabular}

Each crew completed four current operations trials, and ten future operations (transition or advanced) trials: five trials with T-NASA, and five trials without T-NASA. The order of trials within each block was randomized with constraints. Each block contained three nominal trials that represented common taxi scenarios including hold short instructions and route amendments. In addition, each block contained off-nominal taxi events that represented failures or errors in the system. The offnominal scenarios were designed to determine how pilots respond when technologies fail, but more importantly, to better understand how pilots use and integrate the display technologies into their current operations. Three off-nominal events were examined to investigate EMM usage, HUD usage, and clearance information usage. A fourth off-nominal event was tested, but is not discussed in this paper.

EMM Usage - This scenario simulated an unreliability in the surface radar used to generate traffic targets on the EMM. Crew responses to a near-incursion when all but the intruding aircraft appeared on the EMM was compared to when crews had no EMM at all. Crews were not informed of the possible radar failure prior to this experience. This was intended to provide information about how pilots' visual scan may be altered by the presence of the T-NASA technologies. Also this scenario was expected to reveal information about the crews' reliance on the EMM to guide their visual scan of the out-the-window environment.

HUD Usage - In this scenario, the taxi route displayed in the HUD did not coincide with the cleared taxi route, or that presented by the EMM. Much literature has examined the 'cognitive capture' effect [15], which suggests that pilots' attention may be drawn to the HUD at the cost of attending to relevant objects in the out-thewindow view. However, it is unclear how pilots might integrate information from the EMM, ATC, and their first officer to overcome the HUD error, particularly when the HUD presents information that is more relevant than the restricted visibility of the out-the-window view. Following a previous full-mission simulation of the T-NASA system, one captain reported "the biggest problem is when the captain gets really fixed on the HUD and the co-pilot thinks the captain knows exactly what he's doing" [32]. Furthermore, during focus group discussions [14], pilots expressed concerns that if the captain had information in the HUD that the first officer could not see, the first officer would be left 'out of the loop', and not an integral part of taxi operations. This event was devised to provide insight into how captains use the route information in the HUD and the impact of the HUD on crew coordination.

Clearance Information Usage - In this scenario, the taxi clearance issued by ATC contained an error in that the final concourse destination was incorrect. This scenario was devised to better understand how pilots integrate and use the several sources of information that depict the taxi clearance (voice, datalink, and the EMM). It was also designed to investigate the feasibility of issuing airborne taxi clearances, by providing a comparison of error detection ability when clearances are issued airborne versus on the ground. 


\section{PROCEDURE}

Training - Each crew received an instructional package in advance, and viewed a training presentation that provided information about the simulator, and introduced the new operations and technologies. Each crew also completed a 90-min cockpit training session that included an overview of the simulator controls and displays and three land and taxi attempts without the new display technologies. The technologies were introduced incrementally, and crews were given training and practice time with each technology.

Experimental Session - All trials were conducted in lowvisibility (RVR, 1000') at a high-fidelity rendering of Chicago O'Hare airport. Figure 5 depicts the timing and modality of ATC instructions in each of the three deployments (Current Operations, Transition, Advanced). Prior to the start of the experimental trial, the experimenter informed the pilot of both the runway they would be landing on, and their gate and concourse assignment.

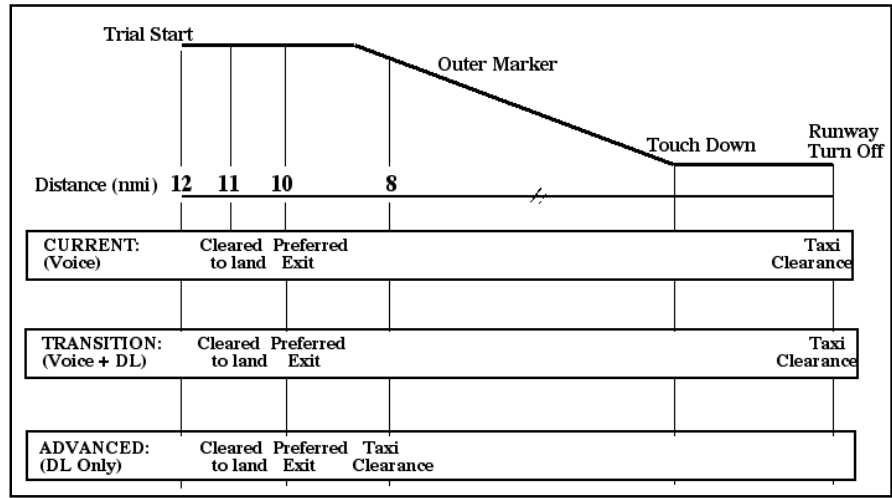

Figure 5. Operational Deployments

Each trial began approximately 12 miles out on a level approach into Chicago O'Hare airport. Pilots performed an autoland, and then taxied to the gate. For all scenarios a preferred exit was provided to the pilots by ATC while airborne. During the training session, pilots were encouraged to take the exit when safe, but it was made clear that they could refuse the exit, or pass by it, if they felt the exit was not safe.

In the current operations scenarios, which were the same for both groups, pilots received all ATC communications via voice. While airborne, pilots received a clearance to land followed by a preferred runway exit. After exiting the runway, pilots were expected to switch to ground frequency and contact ground control for their verbal taxi clearance. Pilots were provided with standard Jeppesen charts for navigation.

In the transition deployment trials, pilots received all ATC communications by both radio and datalink, including the clearance to land, preferred exit, and taxi clearance. Communication between ATC and other pilots on the airport surface could be heard over the radio frequency. For airborne communications (cleared to land and preferred exit), the datalink was transmitted to the crew immediately preceding the ATC voice message. For taxi clearances, the datalink message was transmitted as the aircraft exited the runway, but they did not receive the clearance by voice until they requested it from ATC (consistent with current operations). When T-NASA was available, the taxi route was shown graphically in pending form on the EMM and HUD simultaneous with the datalink transmission. On the EMM, the pending route was shown as white and flashing. On the HUD, the sides of the cleared taxiway were represented by a series of X's. Once pilots accepted the route via datalink, the EMM updated to show a solid magenta route and the HUD X's converted to cones.

In the advanced deployment, pilots received all ATC communications via datalink only. Voice communication was used only for non-routine circumstances that couldn't be resolved via datalink. All other aircraft were also assumed to be operating with a full datalink deployment, so the crews could not hear communication between ATC and other pilots over the radio frequencies. Crews received a clearance to land, preferred exit, and taxi clearance while airborne, all before the outer marker. The datalink transmission was timed, based on pilot input [14] to allow pilots to respond and return their attention to landing the aircraft. After landing and exiting the runway, pilots continued taxiing to the gate and required no further contact with ATC. On trials where T-NASA was available, the EMM showed the pending route (white and flashing) while airborne, that changed to solid magenta once the pilot accepted the datalinked clearance. While airborne, only flightrelevant information was presented in the HUD, then the symbology automatically transitioned to show the cleared taxi route at runway turnoff.

Post-Simulation Debrief - Upon completion of the experimental trials, both crew members completed a questionnaire and participated in a final semi-structured debrief session that solicited further information regarding T-NASA and the operational implementations.

\section{RESULTS}

A wealth of data was collected throughout this highfidelity simulation, however, this report will focus only on a subset of the data. Additional results can be found in [10]. First, the impact of the cockpit displays on nominal taxi performance (speed and navigation errors) will be presented. Following, the results of the three offnominal events will be presented. Where appropriate, 
means are plotted with plus and minus one standard error.

NOMINAL TRIALS - The data from the off-nominal trials were removed from the analyses of nominal trials that follow. The dependent variables were subject to a 2 (deployment group) X 3 (technology) mixed-design analysis of variance (ANOVA). Planned comparisons were conducted using t-tests. Recall that the two deployment groups differed only in the implementation of future operations. The current operation condition served as a baseline condition and was identical for both groups.

Taxi Speed - As shown in Figure 6, the T-NASA displays increased taxi speed by approximately $16 \%$ from $13.9 \mathrm{kts}$ in current operations to $16.1 \mathrm{kts}$, $F(2,24)=12.77, p<.0001$. This increase replicated findings from a previous T-NASA simulation [9] and field research [12]. Not surprisingly, datalink had little effect on taxi speed, increasing speed only slightly to $14.5 \mathrm{kts}$, $p>05$.

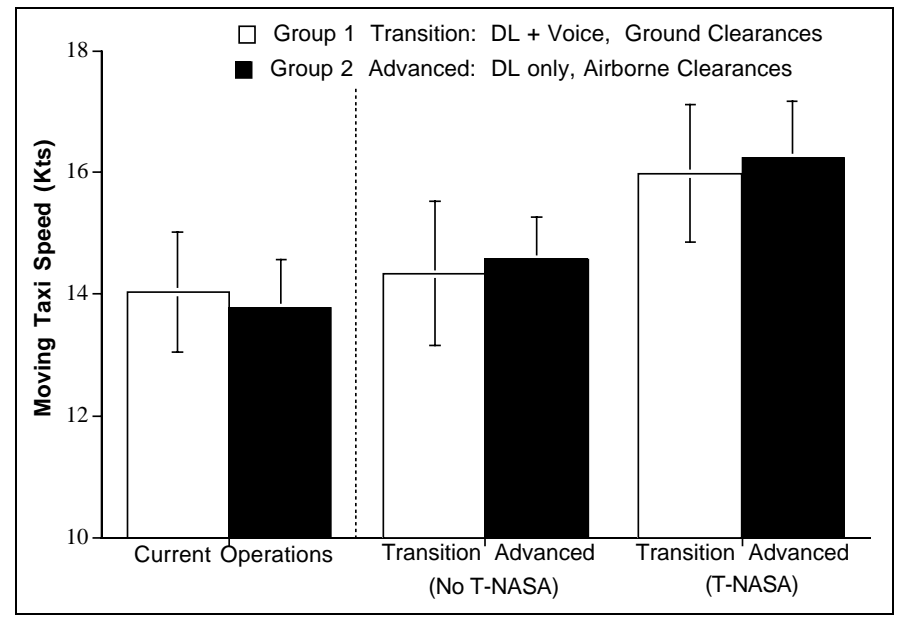

Figure 6. Taxi Speed

Navigation Errors - A navigation error was defined as a deviation from the cleared route by failing to turn or turning incorrectly. In current operation trials, pilots committed an off-route error in $22 \%$ of the trials (Figure 7). With the presence of T-NASA, off-route navigation errors were eliminated completely, replicating previous findings [9]. The effect of datalink on navigation performance has not been previously tested. With datalink, navigation errors occurred on $13 \%$ of trials, which was not significantly less than current operation scenarios, $p>05$.

These findings from the nominal trials replicate previous results and demonstrate that T-NASA successfully attained its goals of increasing taxi efficiency and safety. They also verify that the system's intended benefits have not been jeopardized as a result of the integration into a datalinked environment.

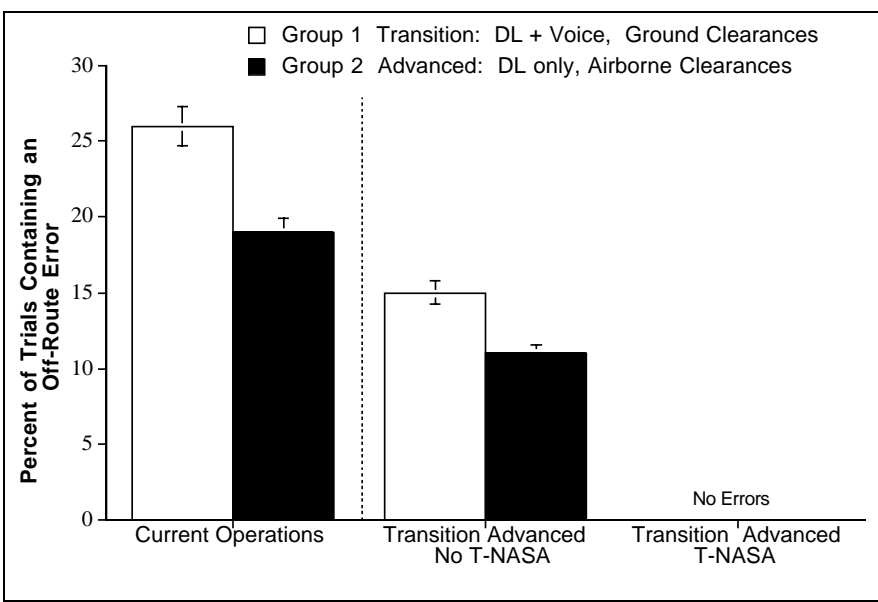

Figure 7. Off-Route Navigation Errors

OFF-NOMINAL SCENARIOS - Three off-nominal events were simulated to gain a better understanding of how pilots integrate the technologies into their procedural operations. The three scenarios, EMM Usage, HUD Usage, and Clearance Information Usage, are discussed below.

EMM Usage - This scenario was intended to assess the degree to which the EMM altered pilots' visual attention to the out-the-window environment. Crew responses to a near-incursion with a GA aircraft when all but the intruding aircraft appeared on the EMM was compared to when crews had no EMM at all. The two incursion scenarios (with and without T-NASA) were matched for factors such as aircraft type, speed of incurring aircraft, and taxiway geometry (both incursion events were conducted on straight sections, with taxiways intersecting at a 90 deg angle).

The distance of the ownship from the incursion intersection when the captain first initiated a braking response was recorded and is presented in Figure 8 . This represented the initial detection of the presence of the GA aircraft.

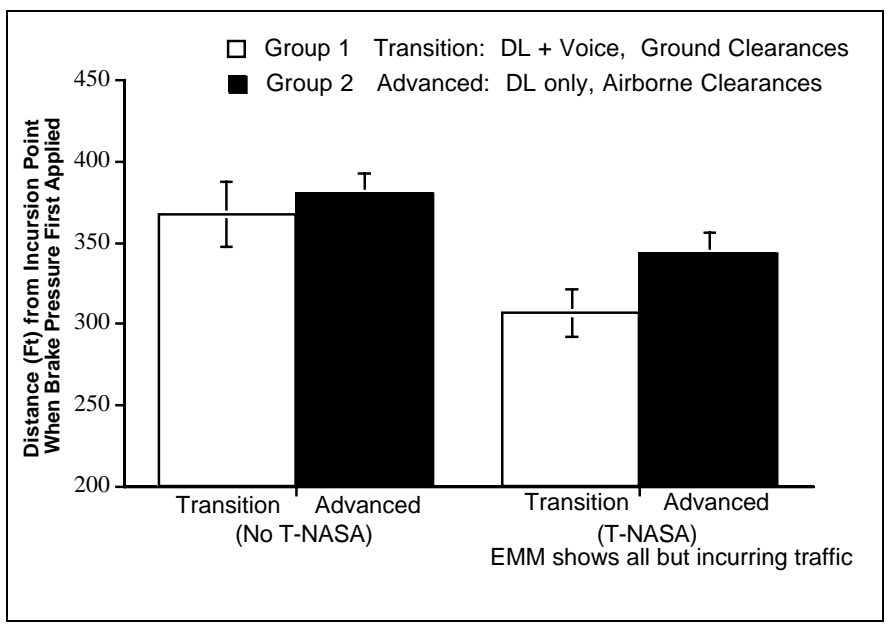

Figure 8. EMM Usage Scenario: Braking Response to Near- Incursion 
The first finding of interest is that there was no difference in braking initiation as a function of deployment approach (transition or advanced), $F(1,16)=3.92$, $p>$.05. That is, although the transition group could hear ATC issue taxi instructions to the GA aircraft via party line communications, they did not brake sooner than the advanced group who could not hear party line communications. Losing this source of traffic awareness information did not detrimentally affect crew performance in this scenario.

The second finding is that the distance from the incursion intersection when braking was first initiated was larger (i.e., pilots began braking sooner) when pilots did not have the EMM at all (No T-NASA) than when they did have T-NASA but the incurring GA aircraft was not depicted on the EMM, $F(1,16)=7.30, p<.05$. Also, an investigation of the maximum deceleration rates, revealed that the deceleration rate was significantly larger for the T-NASA condition $\left(\mathrm{M}=10.46 \mathrm{ft} / \mathrm{sec}^{2}\right)$, than the No T-NASA condition $\left(\mathrm{M}=9.04 \mathrm{ft} / \mathrm{sec}^{2}\right), F(1,16)=$ $14.52, p<.01$. A larger deceleration value is indicative of an increased emergency response consistent with beginning to brake closer to the incursion intersection.

The GA incursion in the T-NASA condition was always presented last. This was done strategically as it was expected that this event would lower pilots' trust in the EMM, which would alter pilot performance on subsequent trials. However, it does raise a potential methodological concern - specifically that after the first near-incursion occurrence pilots may have been cued to the possibility of a second incursion. Indeed, in an investigation of multiple incursion events [33], it was reported that the detection of an event was faster for a second occurrence than the first. Given this finding it would be expected that the braking distances would be larger for the T-NASA condition than the no T-NASA condition that was always presented first. However, the opposite effect was observed, with braking distances for the second event smaller than for the first event. This suggests that the delayed braking response associated with unreliable information depicted on the EMM may actually be a conservative estimate of real world performance.

These data suggest that pilots were able to detect and brake for the intruding aircraft sooner without T-NASA, than if they had T-NASA which did not depict the incurring aircraft. This finding provides information about how pilots use the T-NASA display technology. Observation and discussions with the pilots in the postsimulations debrief suggested that the pilots used the EMM to guide their visual search in the out-the-window environment. As the incurring traffic was not apparent on the EMM, the pilots scan may have been directed to other areas of the airport surface.
HUD Usage - At the conclusion of the final trial, the HUD displayed a system error. The HUD indicated a straight route, but the actual cleared taxi route issued by ATC either by voice or datalink and as shown on the EMM, commanded a turn into the concourse area (depicted in Figure 9). All crews received this as the final turn, on the final trial, in order to mitigate the impact of lowered trust in the system that would be likely on subsequent trials.

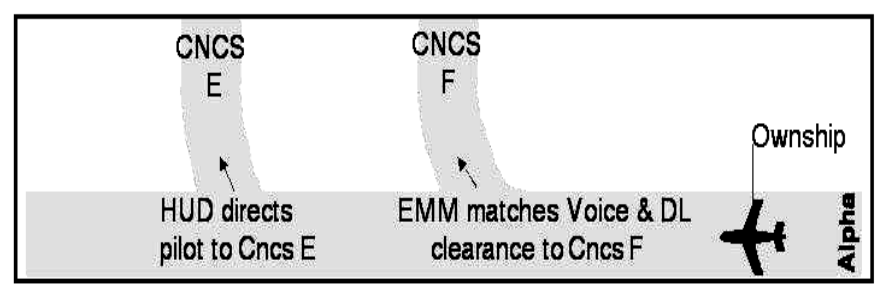

Figure 9. Example of HUD Error

Recall that the captains' ability to detect the HUD discrepancy, as well as the impact on crew coordination of providing information only to the captain via the HUD was of interest. The crews' responses were categorized into one of three route conformance categories. Here, high route conformance serves as a surrogate measure for enhanced navigational awareness and effective crew coordination, as both were required to detect and rectify the discrepancy.

Category 1 - Maintained Full Route Conformance. Seven of the crews $(39 \%)$, turned into the correct concourse without travelling off the cleared route. The first officers in all seven crews took an active role in taxi operations and used the EMM to provide navigation information to the captain, even though the captain had the HUD. This navigation information (i.e., next right turn) cued the captains to the HUD error and facilitated quick detection of the error. During the debrief, the captains reported that they looked through the HUD, saw the centerline and the taxiway sign, and followed it to the gate. These crews used the HUD symbology only when they needed clarification or couldn't see a sign because of poor visibility. This is clearly consistent with the design philosophy of the T-NASA HUD.

Category 2 - Recovered Immediately. Five of the crews (28\%) stopped immediately after leaving the cleared route, usually upon hearing the T-NASA off-route audio alert. These crews quickly clarified the discrepancy, and were able to make a wide turn into their intended concourse. The crews in this category effectively used the EMM and the datalinked clearance information to quickly resolve the taxi clearance discrepancy without requiring re-routing from ATC. Also, all but one of these first officers were 'in the loop' prior to the event, and contributed to early error detection and recovery. 
Category 3 - Required Re-Routing. The remaining six crews (33\%) continued taxiing following the HUD past their cleared taxi route and eventually required re-routing by ATC to return to their concourse. In these cases, the captains seemed to be complacently following the HUD which they sometimes referred to as the 'garden path' or the 'yellow-brick road'. These captains seemed to rely more on the HUD, sometimes even ignoring navigation information offered by their first officers.

In general, the first officers remained active participants in the taxi process and continued to communicate information ascertained from the EMM to the captain. The opposite, however, cannot be said. The captain did not tend to communicate the information in the HUD to their first officers. This finding emphasizes the importance of developing and training crew procedures to accompany cockpit technology integration. Just as in current operations, effective crew coordination must be trained and proceduralized. This holds especially true when new technologies are integrated into the cockpit.

Clearance Information Usage - In one trial per experimental block the clearance contained an intentional error. An example of the clearance that was either datalinked or presented by voice is shown in Figure 10. When available, the EMM depiction also led pilots to the incorrect concourse.

NASA 227:

Taxi to Concourse G via Alpha, Bravo, Concourse E

Figure 10. Example of Clearance Error

This scenario was devised in order to assess pilots' ability to detect the error when issued airborne via datalink instead of on the ground via voice. Additionally, the impact of presenting the clearance graphically via TNASA was also of interest. The clearance was internally inconsistent, leading pilots to an incorrect concourse destination.

A liberal criterion was applied, such that any crew that formally rejected the clearance, queried ATC, or discussed it within the cockpit, was considered to have caught the error. Regardless of error detection, the clearance was amended by ATC $45 \mathrm{sec}$ after the issuance and the discrepancy rectified. Figure 11 shows the percentage of crews that accepted the erroneous clearance. Two patterns of results are of interest. First, errors were almost universally undetected when issued airborne via datalink and second, the datalink and T-NASA technologies did not improve error detection.

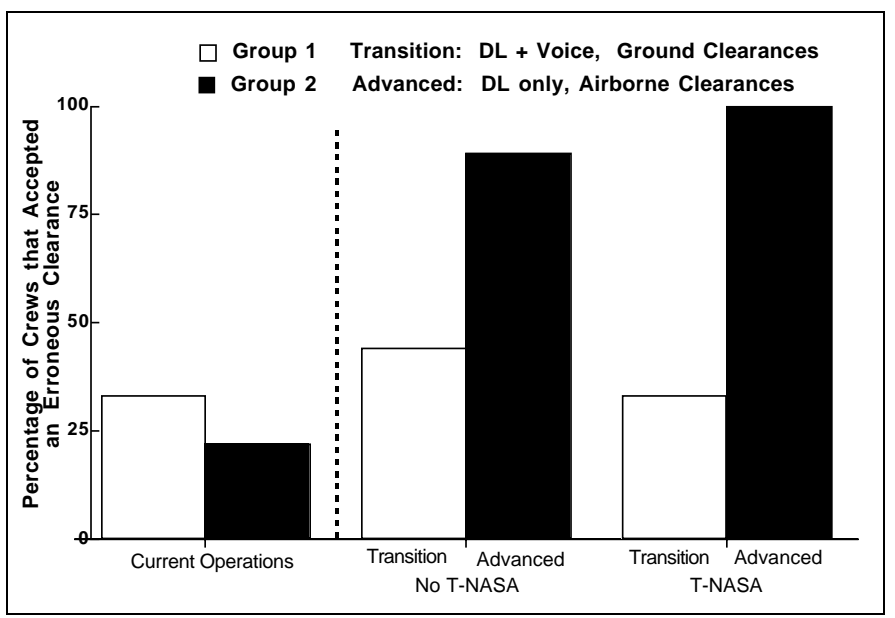

Figure 11. Clearance Information Usage Scenario: Acceptance of Erroneous Clearance

Two explanations are plausible for the low error detection rate of the airborne datalink clearances. First, although pilots accepted the clearance, it is likely that they deferred serious scrutiny and cross-checking until on the ground due to the high workload demands of final approach. Still, $63 \%$ of the pilots reported that if issued before the outer-marker they would prefer airborne clearances over ground clearances. They cited the ability to plan landing and roll-out procedures, smoother braking, and taxi route preview and planning as large advantages of airborne clearances. Furthermore substantial efficiency advantages were realized [as reported in10] because airborne clearances eliminated the need to stop after runway exit, and almost doubled taxi speeds during this typical bottleneck period. These data suggest that the clearance must be issued sooner than the outermarker for the benefits of airborne clearances to be realized. This mandates technologies that provide accurate aircraft position prediction information, and flow algorithms to aid the controller in issuing taxi and gate assignments earlier than is currently possible.

An alternative explanation for the low error detection rate is that the airborne clearances were issued by datalink only. It is possible that presenting clearance information visually rather than aurally may have reduced pilots' ability to detect errors. Without the requirement to hear the clearance, write it, and repeat it back to ATC, the information may not have been fully processed. This issue requires further investigation to better understand the impact of transitioning from voice clearances to datalinked clearances.

The second pattern reflected in Figure 11, is that the datalink and T-NASA technologies did not improve error detection in either the transition or advanced deployment. It may be that the important elements of error checking are hearing, writing, and repeating back the clearance, and that the additional visual information does not help, or may even induce complacency or unwarranted trust. The low error-detection rate, even 
with T-NASA, suggests that the pilots were not making effective use of the multiple sources of clearance information when accepting the taxi clearance, regardless of whether it was issued while airborne or ground.

\section{DISCUSSION}

This final stage in the T-NASA human-centered design process was conducted in order to determine the impact that the T-NASA technologies might have on current operating procedures. The nominal trials revealed that T-NASA may increase taxi speeds by approximately $16 \%$ while simultaneously eliminating off-route navigation errors. However, the off-nominal trials allowed us to delve deeper into the impact that these technologies may have on pilot performance. Determining how pilots operate when faced with system errors provided a wealth of information that may guide the integration of cockpit displays for surface operations.

EMM USAGE - The EMM usage scenario revealed that the EMM is useful in guiding pilots' attention to relevant areas on the airport surface. When automation is reliable, pilots are cued to critical areas of importance and performance may be enhanced. This could increase situational awareness and reduce workload. However, when the automation is unreliable, as may be reasonably expected with surveillance and radar equipment, performance may be degraded.

The EMM usage event represented a scenario where the system may be prone to unreliabilities or errors, but the user is unaware of this potential. These results reflect complacency and over-trust in the automation [34] and are consistent with numerous laboratory studies [i.e., 35, 36] that have demonstrated attentional tunneling due to reliable explicit target cueing at the cost of failing to attend to unexpected higher-priority threats [37]. In contrast, in cases in which automation is unreliable but the user is aware of the system's limitations, the pattern of results may be completely different [37, 38]. Given an opportunity to calibrate cognitive strategies with the actual level of unreliability $[37,38]$, users attend to the raw data underlying the automated cue and also scan a wider pattern around non-cued areas to a greater extent [36]. This suggests that unless ground surveillance is perfectly reliable in its depictions of airport traffic, the pilots must be trained in both the system's capabilities and limitations before it is integrated into the cockpit. As consistent with humancentered design philosophy [2], the human operator must understand how the automation behaves - exactly what the automation does, and why, and how.

These findings also have implications for the interface design of cockpit displays of traffic information such as T-NASA. The designer is faced with difficult choices. On one hand, it may seem prudent to display all airport traffic such as baggage carts and emergency vehicles. On the other hand, this must be weighed against the associated cost of clutter caused by displaying all airport vehicles at a busy airfield. Another design implication that arises is the potential need to display uncertainty information to the pilot $[38,39]$ to allow an accurate calibration of cognitive strategies that guide visual search for traffic. Further work is required to determine how unreliability in surveillance radar should be depicted to allow pilots to maintain effective visual scan strategies.

HUD USAGE - One principle of human-centered design is that each element of the system must have knowledge of the other's intent [24]. Pilots have expressed concerns that providing HUD information to the captain, but not to the first officer, would restrict the first officers' involvement in the navigation process, and lower crew coordination. The result of the HUD usage scenario revealed that all but three of the first officers were actively participating in the navigation process and either prevented the error or enabled a quick recovery. This suggests that although the first officers could not access the information in the HUD, they could use the EMM to maintain effective awareness and crew coordination. This is consistent with the design philosophy: Provide captains with local guidance awareness in the HUD to encourage eyes out taxi, and enable the first officers to gather navigational and traffic awareness by occasional glances to the EMM.

Concerns that the captain and first officer do not share the same mental model of the situation, resulting in a reduction in crew coordination, were not supported. Nonetheless, with the introduction of these technologies, procedures are required to ensure effective crew coordination. Technology is not a panacea, and is certainly not a replacement for adequate crew communications and procedures.

CLEARANCE INFORMATION USAGE - The clearance information usage scenario also provided information about the procedural integration of these technologies into the cockpit. Under nominal conditions, pilots were in favor of airborne clearances and able to process the clearance with enough time to return their attention to landing the aircraft. However, only in the off-nominal scenario containing the clearance error was the potential problem detected. The fact that all but one crew failed to detect the clearance error while airborne suggests that airborne clearances as implemented in this high-fidelity simulation may be problematic. Further work is required to determine when and how this information can be safely presented to the pilots, to realize the benefits of airborne clearances but not jeopardize safety.

Further, concerns were raised about the use of datalink for taxi clearances. Although additional research is required, the findings do suggest that training and 
procedural changes (i.e., procedures to ensure adequate processing and crew communication of datalinked messages) are warranted.

CONCLUSION - The mandate of human-centered automation should be to seek ways in which advanced systems can be made responsive to and consistent with humans [40]. This often means pointing out problems and failures with existing designs, prototypes, or actual operational systems. It is suggested that automation is not perfectly reliable, and perhaps never will be. The answer is not to delay the introduction of these technologies - but rather to make careful decisions regarding the design and implementation of them. The T-NASA display suite shows great promise to increase both the efficiency and safety of surface operations. It has been shown repeatedly that these display technologies can increase taxi speeds while simultaneously reducing navigation errors. The current study revealed information not only about the design of the system and the interface, but also about what airlines must consider in developing training programs and operational procedures associated with the use of these technologies.

\section{ACKNOWLEDGEMENTS}

The development of the T-NASA system was funded by NASA's Terminal Area Productivity Program. The technology has been successfully transferred to NASA's AATT program and further work on intelligent flow algorithms and intelligent interfaces for ground controllers is in progress.

We extend grateful appreciation to George Lawton, Raytheon, for developing the scenario generating environment and data processing tools which greatly enhanced NASA Ames' ACFS facility and enabled testing of the off-nominal events. We also acknowledge Bonny Parke, Kevin Purcell, Susan Dowell, and John Wilson, San Jose State University, for assistance in scenario generation, data collection, and data analysis, and the staff of NASA's ACFS facility for their support of this research. Finally we are grateful to the 42 commercial airline pilots who devoted their time and expertise and the continued support of the participating airlines.

\section{REFERENCES}

1. Foyle, D. C., Andre, A. D., McCann, R. S., Wenzel, E., Begault, D. \& Battiste, V. (1996). Taxiway Navigation and Situation Awareness (T-NASA) System: Problem, design philosophy and description of an integrated display suite for low-visibility airport surface operations. $S A E$ Transactions: Journal of Aerospace, 105, 1411-1418.

2. Billings, C. E. (1996). Aviation automation: The search for a human-centered approach. Mahwah, NJ: Lawrence Erlbaum Associates.

3. Tu, D.S. \& Andre, A.D. (1996). Integration of navigational information for aircraft ground navigation. Proceedings of the Silicon Valley Ergonomics Conference and Exposition, 218-221. San Jose, CA: Silicon Valley Ergonomics Institute.
4. Mejdal, S., \& Andre, A. D. (1996). An evaluation of electronic map display features for aircraft ground navigation. Proceedings of the Silicon Valley Ergonomics Conference and Exposition, 43-52. San Jose, CA: Silicon Valley Ergonomics Institute.

5. Graeber, D. A., \& Andre, A. D. (1999). Assessing visual attention of pilots while using electronic moving maps for taxiing. In R. S. Jensen, B. Cox, J. D. Callister, \& R. Lavis (Eds.), Proceedings of the Tenth Symposium on Aviation Psychology, 791-796. Columbus, Ohio: Ohio State University.

6. McCann, R. S., Andre, A. D., Begault, D., Foyle, D. C., \& Wenzel, E. (1997). Enhancing taxi performance under low-visibility: Are moving maps enough? Proceedings of the 41st Annual Meeting of the Human Factors and Ergonomics Society, 37-41. Santa Monica, CA: Human Factors and Ergonomics Society.

7. McCann, R. S., Foyle, D. C., Andre, A. D., \& Battiste, V. (1996). Advanced navigation displays in the flight deck: Effects on ground taxi performance under low-visibility conditions. SAE Transactions: Journal of Aerospace, 105, 1419-1430.

8. Battiste, V., Downs, M., \& McCann, R. S. (1996). Advanced taxi map display design for low-visibility operations. Proceedings of the Human Factors and Ergonomics Society 40th Annual Meeting, 997-1001. Santa Monica, CA: Human Factors and Ergonomics Society.

9. McCann, R. S., Hooey, B. L., Parke, B., Foyle, D. C., Andre, A. D., \& Kanki, B. (1998). An evaluation of the Taxiway Navigation and Situation Awareness (T-NASA) system in high-fidelity simulation. SAE Transactions: Journal of Aerospace, 107, 1612-1625

10. Hooey, B. L., Foyle, D.C., Andre, A. D., \& Parke, B. (2000, in press). Integrating datalink and cockpit display technologies into current and future taxi operations. To appear in Proceedings of the IEEE/AIAA 19th Digital Avionics Systems Conference. Cambridge, MA: IEEE/AIAA.

11. Young, S. D., \& Jones, D. (1998). Flight testing of an airport surface guidance, navigation, and control system. Proceedings of the Institute of Navigation's National Technical Meeting.

12. Andre, A. D., Hooey, B. L., Foyle, D. C., \& McCann, R. S. (1998). Field evaluation of T-NASA: Taxiway navigation and situation awareness system. Proceedings of the AIAA/IEEE/SAE 17th Digital Avionics System Conference, 47:1 - 47:8.

13. Andre, A. D. (1995). Information requirements for lowvisibility taxi operations: What pilots say. In R. S. Jensen and L. A. Rakovan (Eds.), Proceedings of the Eighth International Symposium on Aviation Psychology, 484488. Columbus, $\mathrm{OH}$ : The Ohio State University.

14. Hooey, B. L., Schwirzke, M. F. J., McCauley, M. E., Renfroe, D., Purcell, K., \& Andre, A. D. (1999). Issues in the procedural implementation of low-visibility landing and surface operation displays. In R. S. Jensen, B. Cox, J. D. Callister, \& R. Lavis (Eds.), Proceedings of the Tenth Symposium on Aviation Psychology, 797 - 803. Columbus, Ohio: Ohio State University. 
15. Weintraub, D. J., \& Ensing, M. (1992). Human factors issues in head-up display design: The book of HUD (SOAR 92-2). Dayton, OH: CSERIAC.

16. Kerns, K. (1990). Data link communication between controllers and pilots: $A$ review and synthesis of the simulation literature. (MP-90W00027). The MITRE Corporation

17. Cotton, J., Schwirzke, M. F. J., Hennessy, R. T., \& Johnson, W. A. (1999). Issues in the Physical Integration of Terminal Area Productivity (TAP) System and Displays into Commercial Aircraft. (Technical Report MTI 99940506-36-2).

18. Andre, A. D., Wickens, C. D., Moorman, L., \& Boschelli, M. M. (1991). Display formatting techniques for improving situation awareness in the aircraft cockpit. International Journal of Aviation Psychology, 1, 205-218.

19. Aretz, A. J. (1991). The design of electronic map displays. Human Factors, 33, 85-101.

20. Foyle, D. C., McCann, R. S., \& Shelden, S. G. (1995). Attentional issues with superimposed symbology: Formats for scene-linked displays. In R. S. Jensen and L. A. Rakovan (Eds.), Proceedings of the Eighth International Symposium on Aviation Psychology, 98-103. Columbus, $\mathrm{OH}$ : Ohio State University.

21. Atkins, M. L., Foyle, D. C., Hooey, B. L., \& McCann, R. S. (1999). Head-up display symbology for surface operations: Comparisons among scene-linked symbology sets for optimum turn navigation. In R. S. Jensen, B. Cox, J. D. Callister, \& R. Lavis (Eds.), Proceedings of the Tenth Symposium on Aviation Psychology, 784-790. Columbus, Ohio: The Ohio State University.

22. Woods, D. D. (1993). The price of flexibility in intelligent interfaces. Knowledge-Based Systems, 6:1-8.

23. Norman, D. (1990). The "problem" with automation: Inappropriate feedback and interaction, not "overautomation". Proceedings of the Royal Society of London B237.

24. Wickens, C. D., Mavor, A. S., \& McGee, J. P. (Eds.). (1997). Flight to the future: Human factors in air traffic control. Washington D.C.: National Academy Press.

25. Weiner, E. L. (1988). Cockpit automation. In E. L. Weiner \& D. C. Nagel (Eds.), Human Factors in Aviation. New York: Academic Press.

26. Sarter, N. \& Woods, D. D. (1995). Strong, silent, and outof-the-loop: Properties of advanced (cockpit) automation and their impact on human-automation interaction. Cognitive Systems Engineering Laboratory, Ohio State University, Columbus, OH, Technical Report CSEL 95-TR01.

27. Lee, J., \& Moray, N. (1992). Trust, control strategies, and allocation of function in human-machine systems. Ergonomics, 35, $1243-1270$.

28. Parasuraman, R., Mouloua, M., Molloy, R., and Hilburn, B. (1996). Monitoring automated systems. In R. Parasuraman, and M. Mouloua (Eds.), Automation and Human Performance: Theory and Applications. Hillsdale, NJ: Erlbaum.

29. Sarter, N. \& Woods, D. D. (1992). Pilot interaction with cockpit automation: Operational experience with the flight management system. International Journal of Aviation Psychology, 2, 303-321.

30. Foushee, H. C., \& Helmrich, R. L. (1988). Group interaction and flight crew performance. In E. L. Wiener \& D. C. Nagel (Eds.,) Human Factors in Aviation. San Diego: Academic Press.

31. Boeing Commercial Airplane Company (August, 1997). Boeing 777 Operations Manual (Chapter 5, Section 40). Seattle, Washington.

32. Parke, B., Kanki, B., McCann, R. S., \& Hooey, B. L., (1999). The effects of advanced navigation aids on crew roles and communication in ground taxi. In R. S. Jensen, B. Cox, J. D. Callister, \& R. Lavis (Eds.), Proceedings of the Tenth Symposium on Aviation Psychology, 804-809. Columbus, Ohio: Ohio State University.

33. Lee, J. D., McGehee, D. V., \& Brown, T. L. (2000). Prior exposure, warning algorithm parameters and driver response to imminent rear-end collisions on a high fidelity simulator. Proceedings of the XIVth Triennial Congress of the International Ergonomics Association and 44 ${ }^{\text {th }}$ Annual Meeting of the Human Factors and Ergonomics Society, 3, 316-319. Santa Monica, CA: Human Factors and Ergonomics Society.

34. Parasuraman, R., \& Riley, V. A. (1997). Humans and automation: Use, misuse, disuse, abuse. Human Factors, 39, 230-23.

35. Yeh, M., Wickens, C. D., \& Seagull, F. J. (1999). Target cueing in visual search: The effects of conformality and display location on the allocation of visual attention. Human Factors, 41, $524-542$.

36. Merlo, J. L., Wickens, C. D., \& Yeh, M. (1999). Effect of reliability on cue effectiveness and display signaling (Technical Report ARL-99-3). Savoy, IL: University of Illinois, Aviation Research Lab.

37. Wickens, C. (2000). Imperfect and Unreliable Automation: Pilot Concerns. Unpublished paper.

38. Parasuraman, R., Sheridan, T. B., \& Wickens, C. D. (2000). A model for types and levels of human interaction with automation. IEEE Transactions on Systems, Man, \& Cybernetics - Part A: Systems and Humans. 30(3), 286 $-297$.

39. Andre, A.D. \& Cutler, H. (1998). Displaying uncertainty in advanced navigation systems. Proceedings of the 42nd Annual Meeting of the Human Factors and Ergonomics Society, 31-35. Santa Monica, CA: Human Factors and Ergonomics Society.

40. Hancock, P. A. (1997). Men without machines. In M. Mouloua and J. M. Koonce (Eds.), Human-automation Interaction: Research and Practice. Mahway, New Jersey: Lawrence Erlbaum Associates. 